\title{
INFLUÊNCIA DO CURSOTÉCNICO PELA ESCOLHA DA GRADUAÇÃO EM ADMINISTRAÇÃO
}

\section{INFLUENCE OF THE TECHNICAL COURSE BY CHOICE OF GRADUATION IN ADMINISTRATION}

\author{
Camilla Cristina de Jesus Ferreira * \\ casodohi@gmail.com \\ Lis Menezes * \\ poslis2016@gmail.com \\ Marcus Vinícius Barbosa* \\ marcus.barbosa1979@gmail.com
}

\author{
Giovana Azevedo Pampanelli Lucas* \\ giopampanelli@gmail.com \\ * Faculdade Sul Fluminense,Volta Redonda/RJ, Brasil
}

\begin{abstract}
Resumo
Este artigo tem como objetivo analisar os motivos que levam os indivíduos a cursar graduação em administração. A questão da escolha profissional no Brasil tem sido ao longo do tempo, um dos assuntos mais explorados por estudiosos das áreas humanas. Foi Super (1957) um dos primeiros a propor uma concepção de escolha profissional com base em conceitos como maturidade, interesses e valores, que indicam um processo de desenvolvimento. Para os alguns, a atual situação do mercado de trabalho, o desejo de consumo e a pressão familiar fazem com que as profissões escolhidas levam em consideração muito mais os aspectos financeiros imediatos do que os sonhos e projetos. Nos últimos dez anos, o ensino de administração vem passando por um processo de ampliação com a criação de novos cursos, fato que vem apresentando, como consequência, o aumento do número de alunos. No geral, as influências com relação à escolha da profissão costumam ser das mais variadas, onde nem sempre a escolha feita para o curso técnico, faz-se uma opção para o Ensino Superior. Compreende-se que pode haver certa influência dos cursos técnicos em administração na escolha do aluno em seguir a carreira de administrador, ou em um segundo momento auxilia o profissional na escolha de outra profissão.
\end{abstract}

Palavras-chave: Administração; Curso técnico; Graduação; Influência;

\begin{abstract}
Payroll-deductible loans are the country's best personal financial credit, and its development was only possible due to the existence of a large network of correspondents in all Brazilian municipalities. Available to employees of INSS public, private, retired and pensioners, its main characteristics are the offered rate, which is the lowest in the market and long term. The general objective of this article is to identify the best methods of capturing and retaining customer loyalty. As a methodology, both the bibliographic research and a case study were used in a Correspondente Bancar Santander, located in the municipality of Volta Redonda / RJ. After quantitative analysis of the data it was possible to identify that the best capture strategy is the indication and the best strategy to keep customers current is the relationship.
\end{abstract}

Keywords: Payroll deductible loans; Captation; Loyalty. 


\section{INTRODUÇÃO}

A definição de uma profissão consiste em um dos passos mais importantes na vida do ser humano, visto que se trata da escolha de atuação e vivência diária. Alguns fatores remetem o individuo a essa escolha: influência, cultura familiar, projeção de carreira e salário, aptidões e/ou interesses pessoais, identidade e perspectiva de trabalho e emprego e sua continuidade, dentre outros. Vale ressaltar, que trata-se de um processo longo da qual exige dedicação e empenho durante o período de formação e posteriormente em sua atuação e desenvolvimento.

Em especial no Curso de Administração, a profissão fora regulamentada pela Lei 4769 (Brasil, 1965). Enquanto ciência social aplicada, o mercado demandará profissionais com senso critico, com vistas ao desenvolvimento e aplicação de estratégia e de profissionais para atuar no campo operacional. Surge assim, além do bacharel em administração, o Técnico em Administração, cujo propósito é dar apoio à ação operacional nas organizações.

Os cursos técnicos surgem como uma opção para atender a demanda de mercado cujo foco consiste em profissionalizar e qualificar a mão-de-obra para atuação, tendo em vista que o mercado necessita de pessoas que possam responder ativamente às demandas empresariais e possuam elementos de conhecimento que ofereça ao aluno uma visão para que este possa conduzir suas atividades e tomar decisões. Dentro do contexto educacional, onde se preza a discussão de teorias e sua relação com práxis, aliado a ações docentes que promovam o crescimento do discente, acredita-se que tais ações dentro do ambiente de aprendizagem, venham a despertar o interesse de o estudante a seguir sua atividade na ciência de administração.

O objetivo geral do artigo versa compreender as motivações na escolha da profissão de Administrador, e identificar se há influência do curso técnico em administração em sua decisão. Ademais, em relação aos Cursos Técnicos em Administração, busca-se identificar motivações, influências, dificuldades e interesses pelos mesmos, além de aferir a carência de ofertas dos cursos na cidade de Volta Redonda. O trabalho se pauta no caminho metodológico das dimensões de pesquisas propostas por Novikoff, (2010), Gatti (2002), tendo como fim a aplicação do conceito de "pesquisaação" à luz de Thiollent (1996), considerando que o escopo da pesquisa se debruça por sobre o levantamento de informações bibliográficas sobre tópicos sobre a evolução da ciência da administração, bem como os pressupostos teóricos que dão ancoragem à ciência, para posteriormente apresentar o caminho metodológico do trabalho, bem como os resultados verificados com a aplicação da pesquisa. 
O trabalho, em suas considerações finais, buscará apresentar um cenário da profissão de Administrador, apontando se houve ou não influencia do curso técnico na opção de escolha de sua graduação, a qual será a base de continuidade de sua atividade profissional. Espera-se ainda, que as discussões ora apresentadas sirvam de base para aprimorar pesquisa acadêmica do curso de administração e afins, para que tal pesquisa venha a embasar qualitativamente outras pesquisas em prol da melhoria da ciência da administração.

\section{1 - SURGIMENTO E EVOLUÇÃO DA ADMINISTRAÇÃO}

Seguindo o constante desenvolvimento e crescimento do mundo como um todo, as relações entre as pessoas e o meio nas quais elas convivem precisam ser cada vez mais estruturadas e organizadas. A necessidade do homem de satisfazer suas próprias exigências e as do grupo social com o qual o mesmo convive deu origem aos primeiros conceitos da administração. Muitos filósofos deixaram contribuições para o pensamento administrativo do Século XX, buscando soluções para os problemas cotidianos em seu meio de vivência. Eles buscaram, em sua época, o que as organizações buscam constantemente: planejamento, organização das tarefas, direção e controle. Em um período tão desglobalizado, houve mais resultados positivos do que muitas empresas que existem hoje em dia. A prática administrativa surge com a ideia de que o homem deixa de ser sozinho para compor um grupo, e assim, como participante desse grupo, deve saber lidar com as consequências dessa mudança. Surge então a necessidade de administrar tarefas e funções básicas para o funcionamento da organização. Compreendese assim, que a administração trata-se de uma atividade inerente à vida humana. Segundo Maximiano, (2007), algumas contribuições deixadas pelos povos da Antiguidade têm extrema relevância, como:

\section{Egípcios Implantação da burocracia administrativa.}

\section{Babilônios Registros de transações comerciais e controle das mesmas.}

Assírios

Depósitos de suprimentos e colunas de transportes, precursores da logística atual.

\section{Gregos Implantação da democracia participativa, planos de} estratégia, conceitos de qualidade, pregação da ética e igualdade na administração. 
Romanos Criadores dos tributos, primeiros organizadores de empresas em outro país e de associações artesanais.

\section{Chineses}

Conceitos de planejamento, comando, doutrina e

estratégia militar.

Fonte: Maximiano, 2007.

Historicamente falando, habitantes de diversos contextos e épocas procuravam meios de melhorar a resolução de seus problemas práticos, dando início à arte de administrar.

No continente americano, as civilizações pré-colombianas, foram grandes sociedades organizadas. Os "descobridores" como Américo Vespúcio e Cristóvão Colombo encontraram campos para uma exploração de recursos naturais, porém se depararam com cidades e economias e sociedades organizadas que já habitavam regiões do então "descoberto" continente americano há centenas de anos, contando com uma rede social extremamente organizada. Astecas, Maias e Incas podem ser destacados como exemplos da existência de uma complexa administrativa, contando com forte estrutura governamental, coordenada por regime monárquico e alguns governos contavam com forte estrutura militar, com o objetivo de atender e dominar territórios tidos como autônomos. Por sua vez, as civilizações Mesopotâmicas e Gregas, que remontam 800 anos A.C. Também já tinham definidas as responsabilidades e funções de toda a população a serviço de seus imperadores. Na civilização Romana a prática da administração se evidencia na expansão do império e nas atividades do governo. Na China, a criação das oito Regras de Administração Pública de Confúcio exemplifica a tentativa chinesa de definir regras e princípios de administração e de se ter um sistema organizado de governo para o império.

Ainda falando de raízes históricas, a Igreja Católica Romana e as Organizações Militares também se destacaram na evolução histórica da administração. A Igreja com a eficácia nas técnicas organizacionais e administrativas que se espalham por todo mundo e exercem influência constante sobre o comportamento pessoal de seus seguidores. Os prelados católicos se destacam como administradores natos. As Organizações Militares apontam para a evolução das ordens dos cavaleiros medievais e dos exércitos mercenários dos séculos passados até os tempos modernos onde existe a atual hierarquia de poder com adoção de práticas administrativas mais concretas.

\section{2 - BREVE HISTÓRICO SOBRE O ENSINO TÉCNICO E PROFISSIONAL NO BRASIL.}


Apesar de muito valorizado nos tempos atuais, os cursos técnicos, de acordo com dados do Ministério da Educação (BRASIL, 2009), remonta há mais de 100 anos. Inicialmente, com foco agrário-exportador, visto a agricultura ser a base de nossa economia, tal formação foi sofrendo transformações ao longo do tempo. Sob o enfoque industrial, os cursos técnicos se consolidam em 1906, por meio do então governador do Estado do Rio de Janeiro Nilo Peçanha. Foi criado por meio do Decreto 787/1906, quatro escolas estaduais com enfoque profissional, sendo três com enfoque industrial e uma voltada à prática agrícola. Denota-se daí a necessidade de uma transição de nossa matriz econômica, saindo do campo para as cidades. A essa época, a nação caminhava a passos lentos para a industrialização. Entretanto, se fazia necessário estabelecer instrumentos de qualificação de mão de obra para atender às demandas crescentes de uma economia que seguia em transformação.

Após sua ascensão à esfera do Federal, por meio do Decreto 7556/1909, Nilo Peçanha cria a Rede Federal de Educação Profissional e Tecnológica, com 19 escolas técnicas, conhecidas como "Escolas de Aprendizes Artífices”. (Brasil, 2009). Vale lembrar que o ensino era vinculado ao então Ministério dos Negócios da Agricultura, Indústria e Comércio.

Posterior a esse fato e principalmente considerando os anos finais e a fase pós Segunda Grande Guerra, o país efetivamente consolidou a figura do ensino técnico profissional, com características próximas ao que hoje temos de oferta nas redes públicas e privadas de ensino profissional. Assim, por meio da Constituição de 1937, conhecida como o "Estado Novo", Getúlio Vargas dá ênfase e o devido valor ao ensino profissional, através do art. 129 da Carta Magna que à época vigorava, tal como segue:

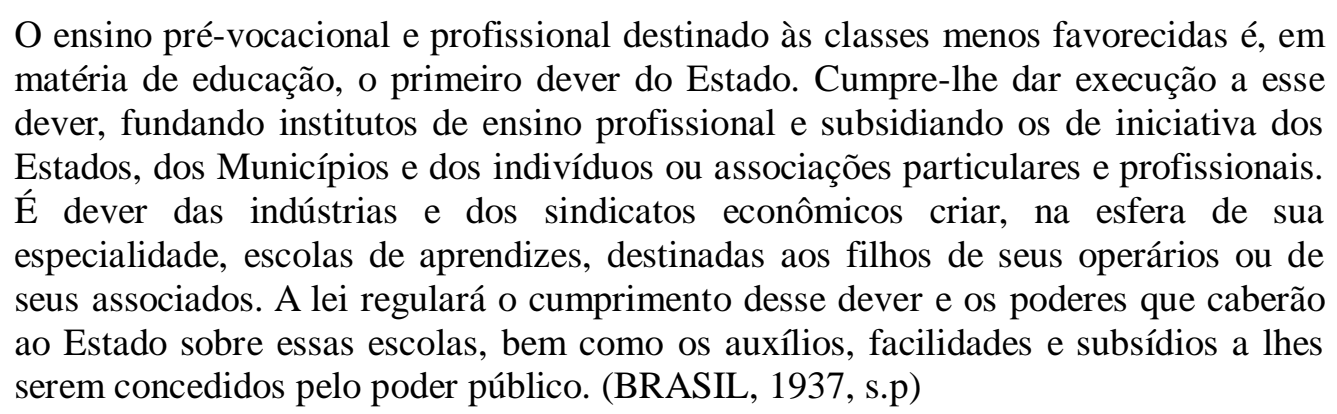

Decerto compreende-se que a função do curso técnico consiste em capacitar o aluno em conhecimentos teóricos e práticos, visando acesso ao mercado de trabalho. Para que essa prerrogativa seja atendida, o aluno deverá ter concluído o ensino médio ou cursá-lo juntamente.

Do período acima relatado até os dias atuais, muita coisa evoluiu em relação a essa modalidade de ensino: o ensino técnico deixou de ser fundamental e passou a ser considerado como curso de nível médio, permitiu acesso aos alunos que porventura os curse acessar o ensino superior. 
A Lei 9394 (BRASIL, 1996), considerada a segunda Lei de Diretrizes e Bases da Educação Nacional, reforçou os preceitos da nova Carta Magna, promulgada em 1988 e destaca a função do ensino técnico profissional como elemento de superação ao assistencialismo, a fim de favorecer a inclusão do cidadão no mercado de trabalho, bem como movimentar e fomentar o crescimento da economia.

\section{3 - O CURSO TÉCNICO EM ADMINISTRAÇÃO}

Após a promulgação da Constituição de 1937, dando abertura ao Estado Novo, o então presidente Getúlio Vargas, visando tornar mais eficiente e racional o serviço público, criou do DASP Departamento Administrativo de Serviço Público, órgão diretamente vinculado à Presidência da República (FGV, 2016). Getúlio inseriu os Cursos de Ciência Contábeis e Ciências Econômicas e estes profissionais formavam a mão de obra do recém criado DASP. Seguindo o movimento, o ensino da Administração, trilhando os caminhos norte-americanos, inicia-se no Brasil um pouco tardio, visto que os Estados Unidos, segundo o site do CFA (2016, s.p) em 1952 "[...] os EUA já formavam em torno de 50 mil bacharéis, 4 mil mestres e cem doutores por ano, em Administração.". Ainda neste ano, o governo cria a EBAPE - Escola Brasileira de Administração Pública da Fundação Getúlio Vargas - FGV (MARTINS,1989), tendo a promulgação da profissão de administrador por meio da Lei 4.769/65 (BRASIL,1965), que regula a profissão de administrador no país.

A partir desse movimento, os profissionais detentores do Ensino Superior passam a ter prerrogativas legais para exercício da profissão no Brasil.

Apesar de não regulamentado pelo Conselho Federal de Administração até a presente data, o Ministério da Educação, com o objetivo de classificar e unificar as nomenclaturas dos cursos Técnicos no Brasil, cria, em 2008, o Catálogo Nacional de Cursos Técnicos - CNCT, onde no eixo de "Gestão e Negócios" se insere o Curso Técnico de Administração (BRASIL,2008).

O Catálogo Nacional de Cursos Técnicos é um instrumento de importante referência para a oferta de cursos técnicos de nível médio, visando disciplinar estas ofertas, possibilitando qualifica-las por parte das instituições de ensino e adquirir maior aceitação no mercado de trabalho.

Através da Resolução CNE/CEB n. ${ }^{\circ}$ 1/2014 (BRASIL,2014) o curso compõem-se de carga horária mínima de 1000 horas, visa que o concluinte compreenda tecnologias associadas aos instrumentos, 
técnicas e estratégias utilizadas na busca da qualidade, produtividade e competitividade das organizações, contemplando o seguinte perfil profissional:

Executam operações administrativas relativas a protocolos e arquivos, confecção e expedição de documentos e controle de estoques. Aplica conceitos e modelos de gestão em funções administrativas. Opera sistemas de informações gerenciais de pessoal e de materiais (BRASIL,2014)

Compreende-se que o curso possibilita uma formação profissional mais prática, a fim de atender necessidades básicas do mercado de trabalho, desta forma, o profissional não costuma assumir cargos de suma responsabilidade afetando diretamente na remuneração imediata. Dado o perfil do egresso, temos que o profissional atua como auxiliar operacional na execução das atividades do cotidiano das organizações.

O Catálogo passa por constantes atualizações feitas pelo Ministério da Educação entre os meses de Agosto e Setembro, após analises das necessidades atuais, sugestões e oferta dos cursos.

Conforme determina a Resolução no 03/2008 do CNE - Conselho Nacional de Educação, o catálogo abre prerrogativa para criação de cursos experimentais que não estejam no catálogo, porém reforçam a necessidade de que estes devem ser inseridos, protocolando requerimento no MEC no período de 1 de agosto a 30 de setembro de cada ano. A resolução ressalta que os cursos que não forem inseridos no CNCT em até 3 anos após o início de sua oferta como curso experimental, não poderão continuar ofertando novas vagas. (BRASIL,2008).

Retomando a citação acerca das funções do profissional técnico de Administração, este possui um vasto campo para atuação e formação nas mais variadas áreas que abrangem o eixo de gestão de modo vertical, podendo prosseguir no campo de Administração a nível superior em diversos cursos, tais como sugere o Catálogo:

Curso superior de tecnologia em processos gerenciais. Curso superior de tecnologia em recursos humanos. Curso superior de tecnologia em marketing. Curso superior de tecnologia em logística. Curso superior de tecnologia em gestão financeira. Bacharelado em administração (BRASIL, 2014, p. 83).

Devido a amplitude das atribuições e possíveis atuações do técnico em administração, citadas no Catálogo, essas possibilitam que o profissional seja dinâmico a fim de dar suporte às operações de diversos setores da organização. Em função dos estudos e temas propostos pelo curso, o profissional técnico em administração pode atuar em instituições públicas, privadas ou optar em ser um profissional 
autônomo, dono do próprio negócio e/ou prestador de serviços de consultoria e suporte. A caracterização da atuação do profissional técnico no que se referem a competências, estudos e habilidades, pode ser verificada na Resolução CNE/CEB N. 04/99 (BRASIL, 1999) que institui as Diretrizes Curriculares Nacionais para a Educação Profissional de Nível Técnico, que enfatiza a amplitude de possibilidades de atuação do profissional.

Vale lembrar que o curso sugerido propõe como eixo de verticalização para sua especialização, informações complementares para avanço de seus conhecimentos, sendo estes devidamente cadastrados no Catálogo Nacional de Cursos Superiores de Tecnologia - CNCST, à exceção do Curso de Bacharelado em Administração, que conta com diretrizes específicas através da Resolução 04/2005 (BRASIL, 2005).

Tal característica e estudo são de suma importância ao profissional em início de carreira no mercado altamente competitivo atualmente, onde profissionais geradores de soluções atingem um nível de satisfação e crescimento diferenciado na empresa. E espera-se que o profissional de administração desenvolva tal perfil.

Para incentivar o ingresso de alunos, seja no Curso Técnico em Administração, seja em outros cursos técnicos oferecidos pelo CNCT, o Governo Federal, instituiu em 2011, por meio da Lei 12.513/2011 o PRONATEC - Programa Nacional de Acesso ao Ensino Técnico e Emprego foi criado pelo Governo Federal do Brasil, em 2011, com o objetivo de expandir, interiorizar e democratizar a oferta de cursos de educação profissional e tecnológica no país. Busca ampliar as oportunidades educacionais e de formação profissional. O público alvo do programa consiste em jovens, em sua maioria que busquem o aprendizado de uma profissão para acesso ao mercado de trabalho e/ou complementação acadêmica, já que pode ser cursado concomitante ao ensino médio regular, e até mesmo buscar aprimorar constantemente seus conhecimentos e qualificação.

Apenas para apontarmos a importância do Curso Técnico em Administração, ano de 2013, atingiu a terceira posição de todos os cursos oferecidos pelo Programa do Governo Federal, conforme aponta quadro 01: 


\begin{tabular}{|l|l|}
\hline \multicolumn{2}{|c|}{ Quadro Cursos da Bolsa-Formaço com mais matrículas em 2013} \\
\hline Cursos Técnicos & Cursos de Formação Inicial e Continuada \\
\hline Técnico em Segurança do Trabalho & Auxiliar Administrativo \\
\hline Técnico em Informática & Operador de Computador \\
\hline Técnico em Administração & Eletricista Instalador Predial de Baixa Tensão \\
\hline Técnico em Logistica & Auxiliar de Recursos Humanos \\
\hline Técnico em Enfermagem & Recepcionista \\
\hline Técnico em Mecânica & Inglês Básico \\
\hline Técnico em Eletrotécnica & Auxiliar de Pessoal \\
\hline Técnico em Redes De Computadores & Almoxarife \\
\hline Técnico em Contabilidade & Manicure e Pedicure \\
\hline Técnico em Edificações & Costureiro \\
\hline
\end{tabular}

Fonte: MEC, 2013.

Assim, para que o aluno e futuro profissional atinja a condição satisfatória de ensino, além da oferta de cursos dentro da área que busca, torna-se também necessária a atualização de conteúdos e proposição de ações inovadoras que levem o aluno ao pensamento crítico-reflexivo, tendo em vista os temas abordados sobre o curso, bem como ofertar bibliotecas com acervo específico e atualizado, laboratório de informática com programas específicos para a prática simulada de ações voltadas ao campo da gestão.

\section{4 - O MERCADO DE TRABALHO DO TÉCNICO EM ADMINISTRAÇÃO}

A realidade do mercado altamente competitivo exige que as pessoas busquem capacitação cada vez mais cedo, bem como comprometimento com a formação acadêmica e direcionamento profissional. Com a globalização, a temática prioritária no campo empresarial passou a ser a competividade, o que faz com que o profissional nos dias de hoje, busque se capacitar e adquirir diferenciais para sua inserção no mercado de trabalho.

É o que afirma Oliveira (1999,p. 65)

As empresas estão valorizando o funcionário criativo, flexível, capaz de se adaptar rapidamente às mudanças [...] No campo da Administração exigese raciocínio lógico, versatilidade e criatividade.

O profissional técnico em administração tem possibilidade de atuar em qualquer área da sociedade em que haja necessidade de gestão, tais como: comércio, fábricas, escolas, organizações da sociedade civil, 
financeiras e órgãos e autarquias do serviço público. Além disso, o CNCT, prevê sugestões de certificação intermediária, tais como:

Agente de Microcrédito. Almoxarife. Assistente de Planejamento e Controle de Produção. Assistente Administrativo. Auxiliar de Faturamento. Auxiliar de Crédito e Cobrança. Auxiliar de Pessoal. Auxiliar de Recursos Humanos. Auxiliar de Tesouraria. Auxiliar Financeiro. Assistente de Marketing. Assistente de Logística. (BRASIL, 2014, p.83.)

Compreende-se que o profissional, tem vasta área de atuação, e a busca pela capacitação profissional mesmo antes da graduação, que o auxilia no crescimento e aprimoramento de seu desempenho dentro da organização, adquirindo experiências que envolvem a operação das atividades. Ademais, trata-se de uma área com boa expectativa de mercado de trabalho por ser ampla, diversificada e necessária em diversas tipos de segmentos de organizações.

De acordo com informações cedidas pelo SENAC - Serviço Nacional de Aprendizagem Comercial, uma das instituições que oferecem o curso pelo PRONATEC, a taxa de empregabilidade de ex-alunos do Curso Técnico em Administração é maior que 70\%, sendo o salário inicial da profissão entre R 917,00 a R\$ 2.900,00 e em média de R\$ 1.768,60. Fonte: SENAC-RJ, 2015-2016.

Em função da continuidade da verticalização da profissão, a revista EXAME de 15/12/2015, destaca que dentre as 45 profissões mais promissoras para 2016, encontramos 11 profissões com ligação direta ao perfil do administrador, sendo estas: Gestor Administrativo/Financeiro, Controller, Gerente de Tesouraria, Gestor de compliance/riscos/auditoria, Gestor de M\&A (Analista de Fusões e Aquisições), Analistas/Gerentes de crédito e risco, Gerente tributário, Diretor financeiro, Gerente e diretor de desenvolvimento de negócios, Gerentes de recursos humanos, Gerente de remuneração, benefícios e folha de pagamento. Por outro lado, dentre as 20 profissões em baixa segundo a mesma pesquisa, não foi identificada nenhuma com perfil direto de administrador. Fonte: Revista Exame.com

Desse modo, tal perspectiva nos possibilita visualizar uma condição favorável para a expansão do campo da administração, sendo o curso Técnico um elemento e/ou critério de decisão para que o profissional concluinte do Curso Técnico em Administração possa se aprofundar após a conclusão do mesmo. 


\section{5 - O PERFIL DESEJADO DO PROFISSIONAL TÉCNICO EM ADMINISTRAÇÃO.}

\section{1 - PERFIL DO INGRESSANTE}

O aluno, ao ingressar no Curso Técnico em Administração, este ingressa, segundo Ribeiro e Bonatto (2006, p.7), por diversos motivos: [...] vocação, afinidade, imposição dos pais, busca pelo status da profissão [...]," porém na maioria das vezes, a busca por uma condição de vida mais satisfatória, através do aprendizado de uma profissão. Ou seja, o curso técnico, tal como outros, pode se tornar uma fonte de oportunidades para o desenvolvimento profissional. Compreende-se portanto que não há um perfil específico para que o aluno ingresse no Curso Técnico, porém não se pode descartar que o aprendizado ao longo do curso deverá formar um perfil dinâmico para que o profissional possa atuar no mercado de trabalho. Assim, podemos compreender que o Técnico em Administração deverá ter o perfil semelhante ao do próprio administrador, tendo em vista, dar suporte ao mesmo em diversas situações.

\section{2 - PERFIL PROFISSIONAL DO EGRESSO}

Em decorrência da formação ampla (multidisciplinar) e das habilidades desenvolvidas, o egresso do curso em Administração em sua graduação deverá estar apto a solucionar problemas ligados às organizações, construindo competências como: planejar e controlar atividades empresariais; planejar os processos de gestão, sejam estes de pessoal, material e/ou de processos diversos; organizar programas de melhorias e redução de custos; analisar os processos financeiros e orçamentários; operacionalizar rotinas administrativas; comunicar-se de forma adequada, possibilidade de relacionar teoria e prática. Tal informação coaduna com o que preconiza a Resolução CNE/CES n. ${ }^{\circ}$ 04/2005, em seu artigo $3^{\circ}$ :

O Curso de Graduação em Administração deve ensejar, como perfil desejado do
formando, capacitação e aptidão para compreender as questões científicas, técnicas,
sociais e econômicas da produção e de seu gerenciamento, observados níveis
graduais do processo de tomada de decisão, bem como para desenvolver
gerenciamento qualitativo e adequado, revelando a assimilação de novas informações
e apresentando flexibilidade intelectual e adaptabilidade contextualizada no trato de
situações diversas, presentes ou emergentes, nos vários segmentos do campo de
atuação do administrador. (BRASIL, 2005, p.2)

Vejam que se por um lado o Administrador tem uma função estratégica e tática, atuando no planejamento das ações, o técnico tem uma função operacional, de execução das ações dos administradores, haja vista 
o que preconiza o CNCT, em consonância com os ditames da Resolução CNE/CEB 001/2014, este fornecerá subsídios para que os administradores possam pautar suas decisões.

Decerto a ação do Técnico em Administração faz-se de suma importância para execução das tarefas administrativas no âmbito de qualquer organização. Então, podemos compreender que o técnico em administração e o administrador são funções totalmente dependentes uma da outra, visto que a ação de um complementa a ação de outro. O perfil do Técnico trata-se de elemento tão relevante que em algumas empresas, mesmo sendo administrador de profissão e estando em função realizada por técnico, o profissional retorna às salas de aula para atender ao perfil estabelecido em sua descrição de cargos e salários.

\section{6 - O REGISTRO NO CRA - CONSELHO REGIONAL DE ADMINISTRAÇÃO}

Para os profissionais formados em Técnico, o Conselho não possui registro, apenas para os profissionais graduados em Administração, o que por vezes pode prejudicar as atividades do Conselho no incentivo de fomentar atividades para que o profissional possa seguir seus estudos na mesma linha profissional.

Recentemente e em função desta demanda, o Conselho Regional de Administração do Estado do Rio de Janeiro (CRA/RJ) submeteu à aprovação o projeto de Lei n 7.493/2014, que prevê a atualização da lei 4.769/1965 e dispõe sobre o registro de Técnico de nível médio em Administração, entre outras providências. O Projeto de Lei propõe a atualização do texto da Lei original regulamentadora $\mathrm{n}^{\circ} 4.769$, de 9 de setembro de 1965, que dispõe sobre o exercício da profissão de Administrador e dá outras providências, para dispor sobre o registro do técnico em Administração nos Conselhos Regionais de Técnicos de Administração (CRTA).

\section{7 - CAMINHO METODOLÓGICO}

Segundo o entendimento de Gatti (2002, p.9) “[...] pesquisa é o ato pelo qual procuramos obter conhecimento sobre alguma coisa”. Desse modo e ainda a luz da autora, “[...] método é ato vivo, concreto, que se revela nas nossas ações, na nossa organização (IDEM, 2010, p.2) no desenvolvimento do trabalho de pesquisa, na maneira como olhamos as coisas do mundo" Devemos ir além dos fatos, não se contentar com o primeiro resultado, mas ir sempre à busca de novas informações. 
Desta forma, o caminho metodológico aplicado no artigo para atingir seus objetivos foi a pesquisa qualitativa.

Para tanto, o presente trabalho pautou-se pela organização de um questionário estruturado, composto de 13 questões objetivas, na qual o entrevistado poderia optar por alguma das respostas, além de graduar em certos momentos, sua percepção com relação às informações listadas, com base em escala de Likert. Para fins de conhecimento, o questionário pode ser verificado ao final do presente trabalho. Visto que fora desenvolvido um questionário e aplicada uma pesquisa a um determinado grupo, consideramos, segundo Thiollent (1996, p.7) como pesquisa-ação, visto que tal pesquisa limita “[...] sua pertinência à faixa intermediária entre o que é geralmente designado com nível microssocial (indivíduos, pequenos grupos)”. Reforça-se o conceito do autor (IDEM, 1996, p.13) visto tratar-se de “[...] pesquisa social com base empírica que é concebida e realizada em estreita associação com uma ação ou tom a resolução de um problema coletivo", onde tal pensamento vai de encontro novamente ao pensamento de Gatti (2002, p.33), onde destaca-se que "a pesquisa nos serve acima de tudo para dar uma base de entendimento sobre uma realidade e a partir disso transformá-la”. (GATTI, 2002, p. 33).

Não somente para obter e ampliar conhecimento a pesquisa também nos auxilia na compreensão da realidade, num melhor entendimento do que nos rodeia e que muitas vezes não entendemos, fazemos então uma pesquisa para melhor se informar e através disto poder dar nossa opinião com base em argumentos pesquisados, abordando dados críticos e através deles dar sugestões de possíveis melhoras, não apenas levantando o problema, mas propor sugestões de melhorias.

\section{8 - CARACTERIZAÇÃo DO LÓCUS DA PESQUISA}

Considerando o objetivo do trabalho, que em verificar se o curso técnico de administração exerce alguma influência na escolha pela graduação, foram aplicados no período de 1 a 8 com alunos dos Cursos de Graduação em Administração na cidade de Volta Redonda, atingindo um grupo total de 129 respondentes.

O formulário fora aplicado de modo presencial em 08 (oito) turmas de duas IES, sendo seus resultados posteriormente tabulados no formulário eletrônico do Google Drive para posteriormente serem postos nas análises dos resultados. 


\section{9 - ANÁLISE DOS DADOS}

No que concerne à faixa etária, temos um grupo relativamente novo, com idades entre 18 e 25 anos, que perfaz $59.7 \%$ do grupo pesquisado, conforme apresenta-se no Gráfico 01:

\section{Gráfico 01 - Faixa Etária do Grupo Pesquisado}

\section{Qual sua faixa etária?}

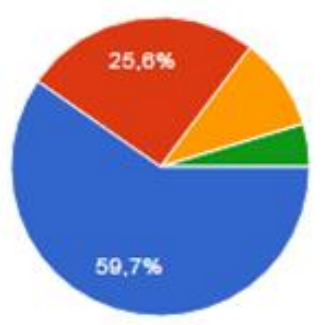

$\begin{array}{crr}\text { Entre } 18 \text { e } 25 \text { anos } & 77 & 59.7 \% \\ \text { Entre } 26 \text { e } 33 \text { anos } & 33 & 25.6 \% \\ \text { Entre } 34 \text { e } 40 \text { anos } & 13 & 10.1 \% \\ \text { Acima de } 41 \text { anos } & 6 & 4.7 \%\end{array}$

Fonte: Elaborado pelos autores.

Através dessa pesquisa, foi possível observar também os períodos mais respondentes e participativos, conforme gráfico 02 :

\section{Gráfico 02 - Períodos do Curso de Administração Pesquisados}

\section{Atualmente, você está em que período ?}

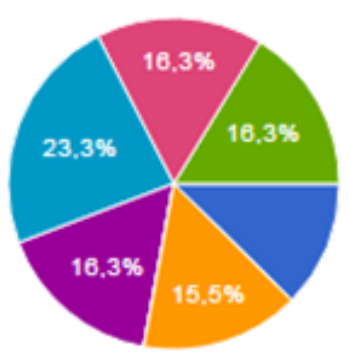

$\begin{array}{rrr}\text { Primeiro } & \mathbf{1 6} & 12.4 \% \\ \text { Segundo } & \mathbf{0} & 0 \% \\ \text { Terceiro } & \mathbf{2 0} & 15.5 \% \\ \text { Quarto } & \mathbf{0} & \mathbf{0} \% \\ \text { Quinto } & \mathbf{2 1} & 16.3 \% \\ \text { Sexto } & \mathbf{3 0} & 23.3 \% \\ \text { Sétimo } & \mathbf{2 1} & 16.3 \% \\ \text { Oitavo } & \mathbf{2 1} & 16.3 \%\end{array}$

Fonte: Elaborado pelos autores.

Nota-se que os períodos mais participativos e engajados no retorno da pesquisa foram os sétimo e oitavo, ou seja, períodos em fase de conclusão do curso de graduação em Administração. O sexto período 
apresentou um maior número de participantes, porém, em análise feita, a pesquisa foi aplicada em duas turmas deste mesmo período, que em média teria 15 participantes por turma respondente.

Por outro lado, foi identificado, que a maioria dos respondentes, sendo estes representados por $61.2 \%$ cursaram Ensino Médio Regular, destacado pelo Gráfico 03:

\section{Gráfico 03 - Formação Ensino Médio dos Respondentes}

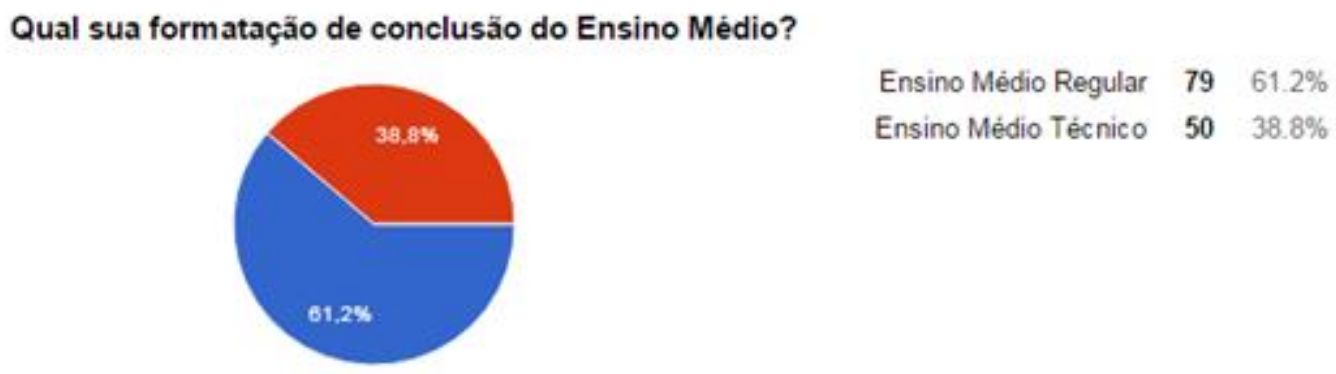

Fonte: Elaborado pelos autores.

Dos estudantes que cursaram algum técnico durante a jornada do ensino médio e/ou posteriormente a finalização, 20 fizeram o técnico em Administração, totalizando 29.9\%, sendo o segundo maior percentual de atuação, porém, sendo minoria se comparado a soma dos demais cursos. O Gráfico 04 aponta ressalta essa informação:

\section{Gráfico 04 - Cursos Técnicos Cursados}

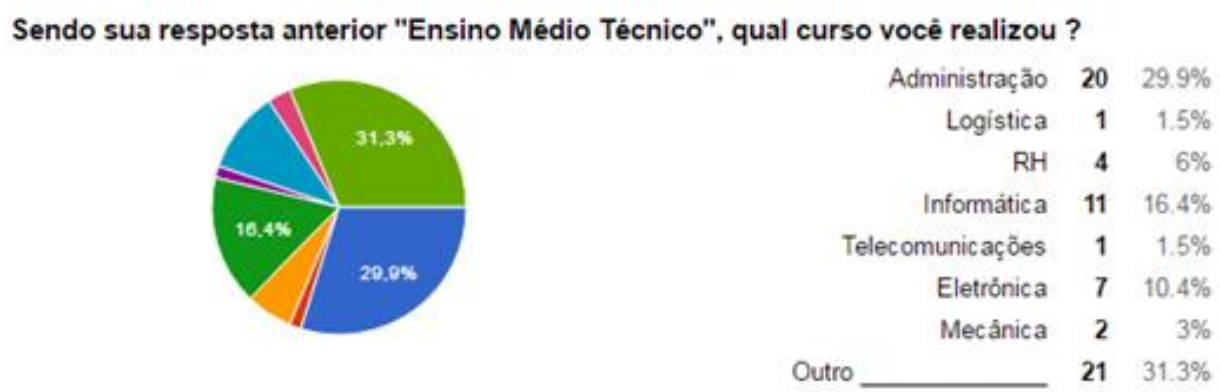

Fonte: Elaborado pelos autores.

Em análise da maioria dos estudantes, que representam 31.3\%, que cursou algum curso não listado (outro), esses, estão distribuídos entre os cursos de Meio Ambiente, Segurança do Trabalho, Telemática e 
Mecatrônica, sendo que nenhum dos citados supera a quantidade de alunos que cursou Técnico em Informática.

Desta forma, foi identificado que o Curso Técnico em Administração tem maior representatividade, no tocante a análise das informações referente aos cursos de forma individualizada.

\section{Gráfico 05 - Percepção sobre a influência do Curso Técnico na Escolha da Graduação}

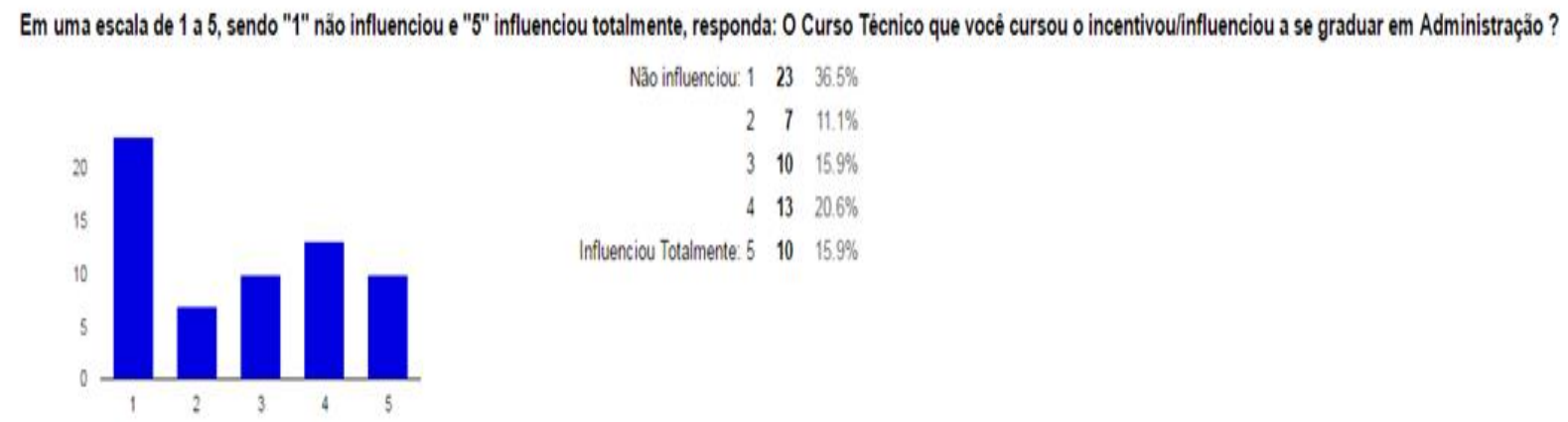

Fonte: Elaborado pelos autores.

Em análise as respostas, foi identificado que a maior parte acredita que o técnico feito anteriormente, não influenciou na escolha da graduação, totalizando $36.5 \%$ dos respondentes.

Em análise dos respondentes entre 1 e 2 que representam "não influenciou”, totalizamos 47,60\% em contrapartida ao respondentes que consideram que "influenciou", que totalizam $36,5 \%$, permanecendo ainda a conclusão de que a maioria considera a não influencia.

Em análise aos 20 respondentes que fizeram o Curso Técnico em Administração, 14 afirmam que foram influenciados na escolha da graduação de administração, 2 não informaram e 4 julgam não terem sido influenciados. Nota-se que a maioria, considera ter sido influenciada.

Percebe-se então, que as motivações para a escolha da graduação não foram influenciadas pelo Técnico, tendo sido outras que podemos apurar no gráfico 06 : 


\section{Gráfico 06 - Motivação para Cursar o Ensino Superior em Administração}

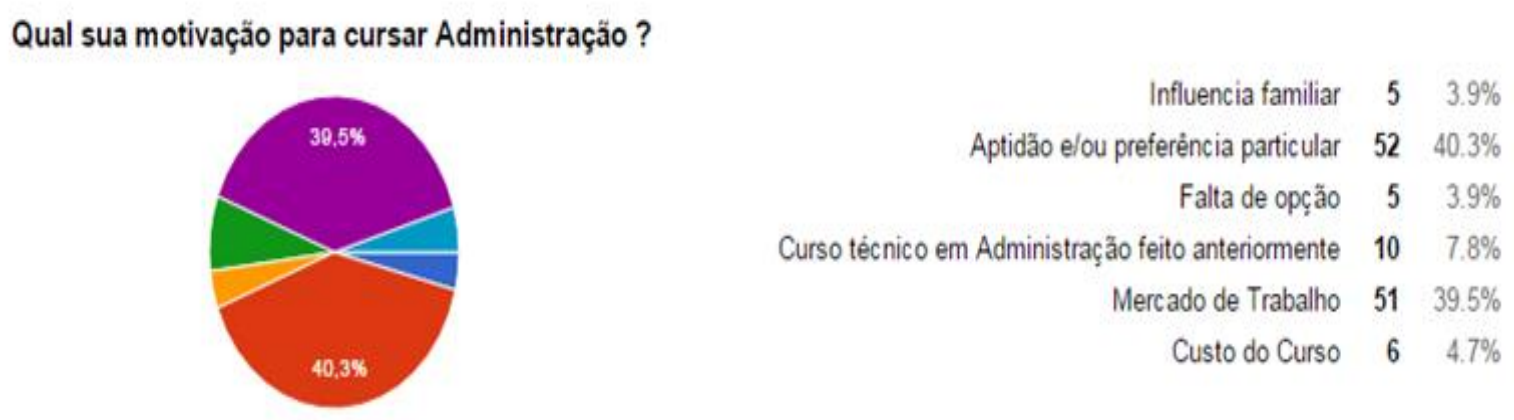

Fonte: Elaborado pelos autores.

Sobre as motivações para cursar Administração, conclui-se que os fatores de maior peso são: aptidão e/ou preferência particular e mercado de trabalho, representando quase $80 \%$ dos resultados se somados.

O fator de maior peso foi o de aptidão e/ou preferência particular para $40.3 \%$ dos respondentes.

O curso de Administração, nesse cenário, apresenta-se ao jovem como uma alternativa viável, que poderá proporcionar-lhe uma posição destacada no mundo de trabalho, por um lado oferecendo-lhe uma diversidade de áreas de atuação, e por outro acalentando seu sonho de atuação profissional independente (ter seu "negócio próprio").

Muitas vezes, esses motivos que levam os alunos a escolherem determinado curso como carreira, não é acompanhada por profissionais especializados (como um psicólogo ou psicopedagogo) e os fazem tomar decisões precipitadas, optando por cursos que lhe forneçam mais possibilidades e variabilidade de emprego ou um que seja de mais fácil acesso e que lhe exija menor esforço para sua realização (AZEVEDO \& FARIA, 2008).

A educação tem como razão o educar e formar pessoas, cidadãos responsáveis e conscientes, prover espaço para constante aprendizagem dos indivíduos e promover e difundir conhecimentos a partir de pesquisas contribuindo para o desenvolvimento, melhoria e proteção dos valores da sociedade. O papel da universidade é este, o de criar conhecimentos não só a partir do saber cientifico, mas ser capaz de criar hábitos, costumes e culturas formando um cidadão crítico e capaz de intervir na sociedade a qual pertence (OLIVEIRA, 2004). Atualmente, o ingresso na universidade é visto como se fosse o único caminho para "ser alguém na vida". O maior desejo do jovem hoje é poder se realizar profissionalmente e dar continuidade aos seus estudos para cada vez tornar-se melhor e ser capaz de enfrentar a competitividade crescente do mercado de trabalho emergente. Percebemos nos dados com os 
pesquisados que ainda há certa influência da situação do mercado de trabalho como determinante na escolha da profissão, o que pode ter certo risco, visto que a volatilidade do capitalismo e do mundo do trabalho tem alterado e flexibilizado as profissões clássicas atualmente. Isso se deve à inversão de papéis sobre a função do ensino médio na formação cidadã do aluno, deixando de ser integradora social e tornando-se simplesmente uma preparação para o vestibular (BRASIL, 1996; SPARTA \& GOMES, 2005).

A terceira opção mais votada seria o fato de ter cursado o técnico em Administração anteriormente, porém, apresentou baixa representatividade, totalizando $7.8 \%$.

Ao questionar o grupo pesquisado sobre a possíbilidade deste cursar um curso técnico, a maioria dos respondentes destacou que não tiveram interesse em realizar o curso anteriormente, representado por $58.9 \%$ e diferente em $17,8 \%$ se relacionado a porcentagem dos interessados.

\section{Gráfico 07: Interesse no Técnico em Administração}

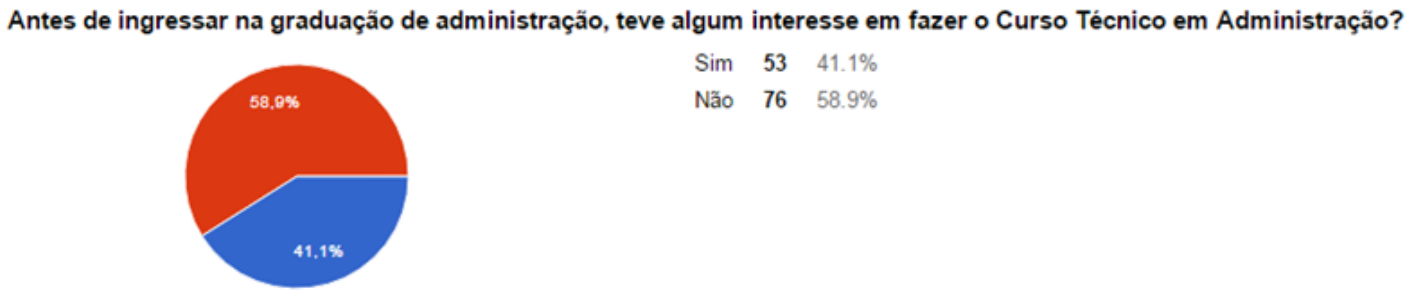

Fonte: Elaborado pelos autores.

Outro ponto observado na pesquisa, foi encontrar foi a falta de conhecimento em relação ao curso, seguido do custo do mesmo. Considerando as observações acima, identifica-se um déficit de informações relacionadas ao curso, somado ao custo considerado elevado.

As demais opções analisadas apresentaram pequena diferença entre si, no tocante as porcentagens apuradas, sendo relativa de $1,7 \%$ a $3,3 \%$, conforme gráfico 08 : 


\section{Gráfico 08: Dificuldades na tentativa de realização do técnico em administração}

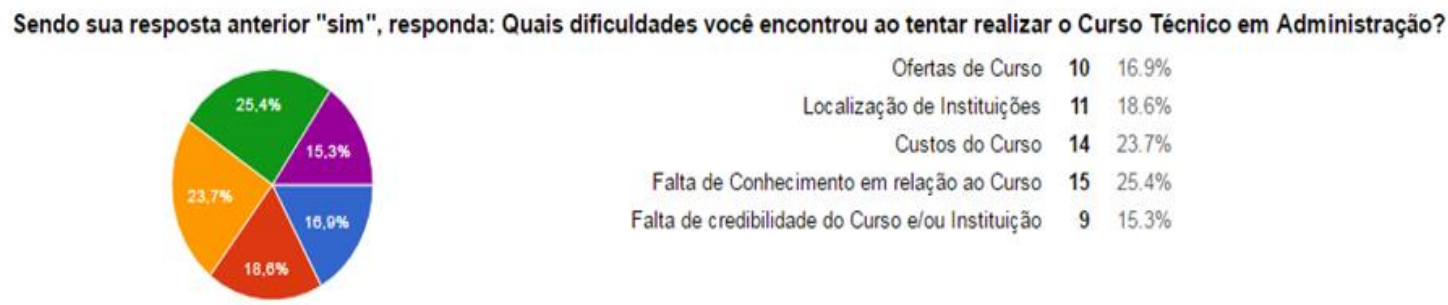

Fonte: elaborado pelos autores.

Faz-se compreender, a partir da pesquisa ora aplicada, um aumento tendencioso na demanda de cursos profissionalizantes, principalmente para aqueles que pretendem obter maior qualificação profissional, mas que não tem acesso a cursos superiores de formação. Compreende-se que cada vez mais é preciso oferecer aos alunos do ensino médio uma orientação vocacional e esclarecimentos sobre o papel do ensino superior e a relação com a escolha da profissão.

Foi realizada pelos autores, uma pesquisa através de contatos telefônicos em instituições da cidade, a fim de verificar a oferta dos cursos técnicos em administração, bem como informações sobre custos dos mesmos. Foi apurados custos entre as faixas de $R \$ 124,00$ a $R \$ 445,00$. Nota-se que a falta de conhecimento sobre o curso, pode ter representação ainda na informação relativa a custos, que podem variar de acordo com a instituição.

Observa-se ainda que dos alunos que se interessaram pelo Técnico, sendo estes $41,1 \%$, encontraram dificuldades relacionadas a falta de informação sobre o curso.

Por outro lado, sendo um dos pontos altos da pesquisa, que os alunos consideram que o curso técnico, independente da área, influencia na escolha da graduação, sendo estes representados por 69\% dos respondentes. 


\section{Gráfico 09: Influência do técnico na escolha da graduação}

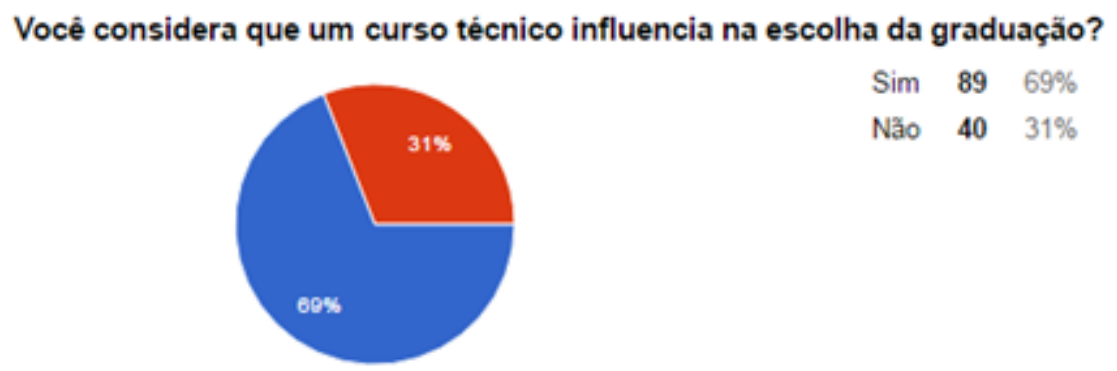

Fonte: elaborado pelos autores.

Complementarmente foi questionados aos alunos se estes consideram importante cursar um curso técnico, independente da área, antes do ingresso na graduação escolhida, sendo estes representados por $62.8 \%$ dos respondentes.

\section{Gráfico 10: Importância do técnico antes do início da Graduação}

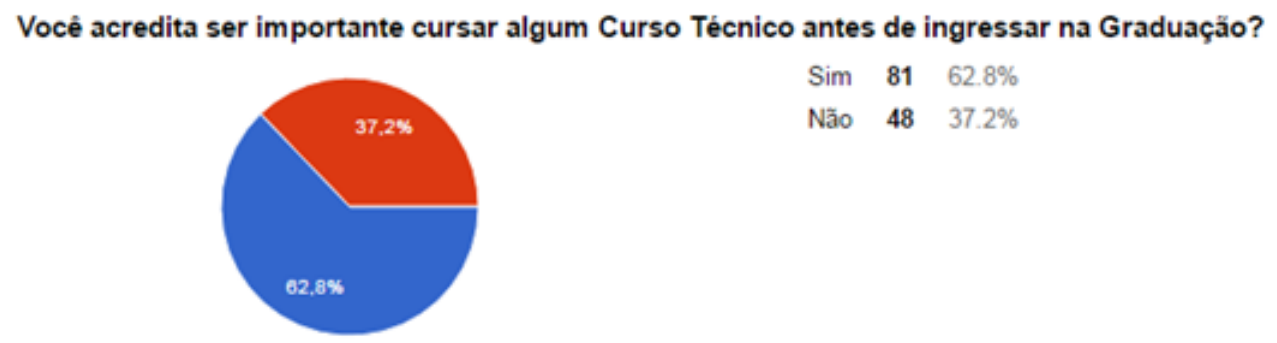

Fonte: Elaborado pelos autores.

Por fim, predomina, com quase $90 \%$ de retorno positivo, que o profissional formado em técnico de Administração carrega boa bagagem para iniciar a graduação em Administração.

O fato de cursar um técnico antes da graduação sendo este na mesma área possibilita obter informações prévias relevantes sobre a evolução do ensino ao longo de sua graduação, durante seu percurso acadêmico. 


\section{Gráfico 11: Bagagem do profissional formado em Técnico em Administração}

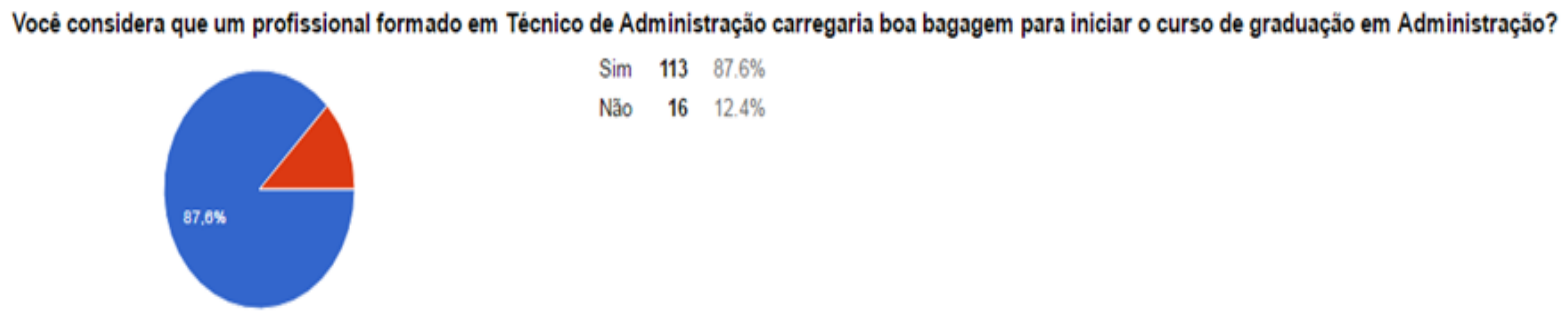

Fonte: Elaborado pelos autores.

Apesar de muitos dos discentes não terem cursado um curso técnico em administração, a maioria dos pesquisados consideram coo sendo de extrema relevância ter realizado um curso técnico em administração. A seguir a análise crítica consolida as percepções acerca do estudo.

\section{0 - ANÁLISE CRÍTICA}

No que concerne à faixa etária, temos um grupo relativamente novo, com idades entre 18 e 25 anos, que perfaz $59.7 \%$ do grupo pesquisado. Nota-se que os alunos, não apresentaram demora relevante para ingressar na universidade, visto que o ingresso se dá ao final da conclusão do Ensino Médio, que regularmente deveria ser finalizado até os 19 anos, conforme meta do Programa Todos pela Educação (2014).

O gráfico 1 analisado destaca que apenas 4,7\% estão inseridos na faixa etária acima de 41 anos.

Em análise a predominância de respondentes terem cursado Ensino Médio Regular, isso se deve à inversão de papéis sobre a função do ensino médio na formação cidadã do aluno, deixando de ser integradora social e tornando-se simplesmente uma preparação para o vestibular (BRASIL, 1996; SPARTA \& GOMES, 2005). Nota-se que os estudantes focam diretamente em finalizar o ensino básico, sem a preocupação do curso profissionalizante.

O aluno herda do Ensino Médio o sentimento de que a escolarização é o caminho para a melhora de sua condição de vida. (FREIRE, 1978, p.66-68). Ingressa no curso superior para tornar mais próximo seu sonho de ascensão profissional. 
Em relação a opção aptidão e/ou preferência particular, sendo a de maior predominância entre os respondentes, Romanelli (1995) explica que a razão pela qual uma pessoa decide por determinada carreira pode estar relacionada a fatores como a preocupação com a sua própria profissionalização, ou seja, o indivíduo procura adquirir novos conhecimentos e habilidades apenas para adequar-se ao mercado de trabalho, neste ponto, a satisfação pessoal e a realização profissional ficam em segundo plano. Outro fator é a vocação que o indivíduo atribui a si, para desempenhar determinada função, quanto a isso, a satisfação pessoal está em primeiro lugar, pois é algo que para ele, tem valor próprio.

Leventus e Nunes (2002, p.62) colocam que a justificativa de escolha baseada nesse argumento é uma comprovação de que nesse momento "o jovem está definindo sua identidade: quem ele quer ser e quem não quer ser", considerando a futura escolha profissional a partir de seus interesses, daquilo que gosta e que pensa que pode realizar".

Para Bohoslavsky (1977, p. 48-49) o adolescente busca, nas ecolha profissional, "a realização pessoal, a felicidade, a alegria de viver”. A mesma opinião é compartilhada por Castanho (1988, p. 10); “Quando alguém procura uma profissão, buscal algo que o faça feliz”.

Bohoslavsky (1977, p. 157-165), a partir de análise de estudos com adolescentes em processos de escolha de carreira, afirmando que grande parte de conflitos dos adolescentes refere-se à deficiência de informações. Reconhece que possuem "mais informações do que pensam", porém são informações distorcidas - conhecimentos parciais (limitados, por exemplo, à visão dos professores com quem tiveram contato), confusos e preconceituosos, despertando-lhes um sentimento de ansiedade, que por sua vez pode leva-los a estereotipar ainda mais os conhecimentos que possuem.

Em análise as perguntas em relação a influência do curso técnico na escolha da graduação, foi observado que existe uma contradição de fatos, visto que em uma das questões, os alunos que cursaram algum técnico, julgam não terem sido influenciados por ele na escolha da graduação. Porém, em pergunta posterior se consideram que um curso influencia, a maioria dos alunos, representada por $69 \%$, considera que o curso técnico gera influencia na escolha da graduação.

\section{CONSIDERAÇÕES FINAIS}

Conseguimos compreender que o jovem ou adolescente escolhe o curso de administração a partir de valores pessoais absorvidos através de fontes de informações obtidas individualmente e este artigo teve por objetivo analisar os motivos que levam esses alunos a cursar graduação em administração se considerarmos os cursos técnicos feitos anteriormente ou não. Observou-se que a maioria dos alunos entrevistados acredita que o curso técnico influencia na tomada de decisão e gera boa bagagem para 
início da graduação. Ressalta-se que apesar das divergências nas respostas em alguns itens, predomina o retorno positivo de que o técnico em Administração fornece informações primárias e relevantes sobre o tema que servirão de base durante a jornada acadêmica. Dessa forma, além de identificadas as motivações, influências e dificuldades, podemos compreender que mesmo que parte dos estudantes não tenha sido influenciada pelo curso técnico, a visão e aceitação geral do curso é bem vista pelos alunos. A percepção dos alunos em relação ao técnico vinculado a graduação, em sua primazia, é de que o técnico pode auxiliar na condução da carreira administrativa com conhecimentos prévios relevantes.

\section{REFERÊNCIAS}

ADMINISTRADORES.COM, A influência dos filósofos na administração. Disponível em: http://www.administradores.com.br/artigos/economia-e-financas/a-influencia-dos-filosofos-naadministracao/25128/ Acesso: 25/06/2016.

AZEVEDO, A. S. \& FARIA, L. Motivação, sucesso e transição para o ensino superior. Psicologia, v.20, n.2, p.69-93, 2006.

BOHOSLASVSKY, Rodolfo. Orientação vocacional: a estratégia clínica. São Paulo: Martins fontes, 1993.

CARDOSO, Ruth C. L; SAMPAIO, Helena. Estudantes Universitários e o trabalho.

CHIAVENATO, Idalberto. Introdução à teoria geral da administração. Elsevier Brasil, 2003. . Recursos Humanos na Empresa. 3. ed. São Paulo: Atlas, 1994. . Teoria Geral da Administração. 3. ed. São Paulo: Atlas, 2004. . Teoria Geral da Administração. 7. ed. São Paulo: Elsevier, 2003. .Introdução à administração. São Paulo: Thomas Learning, 2006.

CRA-RJ, Conselho Regional de Administração do Rio de Janeiro. Disponível em: http://www.crarj.adm.br/ Acesso: 18/06/2016

DIEHL, Astor Antonio. Pesquisa em ciências sociais aplicadas: métodos e técnicas. São Paulo: Prentice Hall, 2004.

DRUCKER, Peter. (1981). Prática da administração de empresas. Cengage Learning Editores. . Desafios gerenciais para o século XXI. Pioneira, 1999. 
O melhor de Peter Drucker: O homem, a Administração e a sociedade. $7^{\text {a }}$ Ed. São Paulo: Nobel, 2006.

FREIRE, Paulo. Pedagogia do oprimido. Rio de Janeiro: Paz e Terra, 1978.

GATTI, Bernardete Angelina. A construção da pesquisa em educação no Brasil. Brasília: Editora Plano, 2002.

GUIA DO ESTUDANTE, Curso técnico e faculdade de Administração são a mesma coisa? Disponível em: http://guiadoestudante.abril.com.br/orientacao-vocacional/consulte-orientador/curso-tecnicofaculdade-administracao-sao-mesma-coisa-738160.shtml Acesso: 15/06/2016.

IBGE, Século XX. Disponível em: http://seculoxx.ibge.gov.br/images/seculoxx/seculoxx.pdf Acesso: 30/06/2016.

IFNMG, Técnico em Administração. Disponível em: http://www.ifnmg.edu.br/cursos/105portal/ensino/ead/2381-tecnico-em-administracao Acesso: 25/06/2016.

INEP, Resumo Técnico do Senso da Educação Superior. Disponível em:

http://download.inep.gov.br/download/superior/censo/2013/resumo_tecnico_censo_educacao_superior_2 013.pdf Acesso: 26/06/2016

LEVENFUS, Rosane S,; NUNES, Maria Lucia T. Prinicpais temas abordados por jovens centrados na escolha profissional. In: LEVENFUS, Rosane S. SOARES, Dulce H. P. Orientação vocacional opcupacional: novos achados teóricos e instrumentais para a clínica, a escola e a empresa. Porto Alegre: Artes Médicas, 2002, cap. 4, p. 67-78.

MAANEN, John Van. Reclaiming qualitative methods for organization reserch: a preface. In Administrative Science Quarterly, Vol. 24, 1079. Disponível em: http://www.ead.fea.usp.br/cadpesq/arquivos/C03-art06.pdf Acesso: 07/05/2016.

MEC, Consulta Pública das Escolas e Cursos Técnicos Regulares nos Sistemas de Ensino e Cadastradas no MEC. Disponível em: http://sistec.mec.gov.br/consultapublicaunidadeensino/\# Acesso: 26/06/2016.

Meta 4 Todos pela Educação. Disponível em:

http://www.todospelaeducacao.org.br/biblioteca/1533/meta-4-do-todos-pela-educacao---dados/ Acesso em 04/06/2016.

MINISTÉRIO DA EDUCAÇÃO. Mulheres são maioria no ingresso e conclusão de cursos superiores. Disponível em http://www.brasil.gov.br/educacao/2015/03/mulheres-sao-maioria-no-ingresso-e-naconclusao-de-cursos-superiores Acesso: 20/06/2016.

NOVIKOFF, C. Pesquisa qualitativa: uma abordagem teórico-metodológica na educação. Disponvel em: http://www.sepq.org.br/IVsipeq/anais/artigos/52.pdf Acesso em: 06/06/2016. 
OLIVEIRA, Sílvio Luiz de. Sociologia das Organizações: uma análise do homem das empresas no ambiente competitivo - São Paulo: Pioneira, 1999.

PRONATEC, Expansão da Rede Federal de Educação Profissional, Científica e Tecnológica. Disponível em http://pronatec.mec.gov.br/cnct/et_gestao_negocios/t_administracao.php Acesso: 15/06/2016.

\section{REVISTA EDUFOCO, ALGUMAS CONSIDERAÇÕES SOBRE PROCEDIMENTOS METODOLÓGICOS NAS PESQUISAS EDUCACIONAIS. Disponível em: http://www.ufjf.br/revistaedufoco/files/2010/02/07.pdf Acesso: 27/06/2016.}

REVISTA EXAME.COM. 45 Profissões e Carreiras Promissoras para 2016. Disponível em: http://exame.abril.com.br/carreira/noticias/45-profissoes-e-carreiras-promissoras-para-2016\#47. Acesso em 12/05/2016.

ROMANELLI, G. O significado da educação superior para duas gerações de famílias de camadas médias. R. Bras. Est. Pedag., v.76, n.184, p.445-476, set-dez. 1995.

ROSENTAL, Claude; FRÉMONTIER-MURPHY, Camille. Introdução aos métodos quantitativos em ciências humanas e sociais. Porto Alegre: Instituto Piaget, 2001.

SEBRAE NACIONAL, 2016. Conheça características importantes para o comportamento empreendedor. Disponível em: http://www.sebrae.com.br/sites/PortalSebrae/artigos/conhecacaracteristicas-importantes-para-o-comportamentoempreendedor,638b5d27e8fdd410VgnVCM1000003b74010aRCRD. Acesso em 12/05/2016.

SEBRAE, SERVIÇO BRASILEIRO DE APOIO ÀS MICRO E PEQUENAS EMPRESAS. Disponível em: http://www.sebrae.com.br/br/home/index.asp Acesso: 20/06/2016.

SENAC, Mercado de trabalho carente de técnicos administrativos. Disponível em: http://www.ead.senac.br/noticias/2013/07/mercado-de-trabalho-carente-de-tecnicos-administrativos/ Acesso: 17/06/2016.

SENAC/RJ, O Técnico em Administração. Disponível em http://www.rj.senac.br/cursos/administracaoe-financas/tecnico-em-administracao. Acesso em 12/05/2016.

SILVA, R. O. Teorias da Administração. São Paulo: Pioneira Thomson Learning, 2001.

SPARTA M. \& GOMES, W. G. Importância atribuída ao ingresso na educação superior por alunos do ensino médio. Revista brasileira de Orientação Profissional, v.6, n.2, p.45-53. 2005.

THIOLLENT, Michel. Metodologia da Pesquisa-ação. $7^{\circ}$ edição. Editora São Paulo: Cortez; 1996. 
UNIVATES, Administração. Disponível em: https://www.univates.br/tecnicos/administracao Acesso: 26/06/2016.

Recebido em: 18/08/2016

Aceito em: 21/06/2017

Endereço para correspondência:

Nome: Camila Cristina de Jesus Ferreira

e-mail: casodohi@gmail.com

Este obra está licenciada com uma Licença Creative

Commons Atribuição 4.0 Internacional. 